\title{
Palmar hyperhidrosis: clinical, pathophysiological, diagnostic and therapeutic aspects*
}

\author{
Flávio Ramalho Romero ${ }^{1}$ \\ Hélio Amante Miot ${ }^{1}$
}

\author{
Gabriela Roncada Haddad ${ }^{1}$ \\ Daniele Cristina Cataneo ${ }^{1}$
}

DOI: http:/ / dx.doi.org/10.1590/abd1806-4841.20165358

\begin{abstract}
Palmar hyperhidrosis affects up to 3\% of the population and inflict significant impact on quality of life. It is characterized by chronic excessive sweating, not related to the necessity of heat loss. It evolves from a localized hyperactivity of the sympathetic autonomic system and can be triggered by stressful events. In this study, the authors discuss clinical findings, pathophysiological, diagnostic and therapeutic issues (clinical and surgical) related to palmar hyperhidrosis.
\end{abstract}

Keywords: Botulinum toxins; Cholinergic antagonists; Hyperhidrosis; Sweating; Sympathectomy; Pulsed radiofrequency treatment

\section{INTRODUCTION}

Primary or essential hyperhidrosis is a disorder characterized by excessive, chronic, sweating acquired during rest, unrelated to the need of heat loss of the body. It can affect one or more areas of the body, occurring predominantly in the hands, armpits, feet, head and also in the inguinal region. ${ }^{1-3}$

The prevalence of primary hyperhidrosis $(\mathrm{PH})$, according to the literature, ranges from $1 \%$ to $3 \%{ }^{4,5}$ It occurs in all seasons, including winter. In situations of stress, anxiety, fear and nervousness, there is worsening of symptoms. $\mathrm{PH}$ nomenclature is related to the anatomical locations: face and scalp (craniofacial hyperhidrosis), palmar region (palmar hyperhidrosis), armpits (axillary hyperhidrosis), inguinal region (inguinal hyperhidrosis) and plantar regions (plantar hyperhidrosis). ${ }^{6,7}$

It affects men and women, although there is a false impression of a predominance among female due to increased demand for treatment by women..$^{4-6}$ Clinical recognition usually occur until the third decade of life, usually before 25 years, and may be earlier in individuals with palmar and axillary hyperhidrosis, who manifest the symptoms in childhood and adolescence. ${ }^{5,6}$ In addition, higher prevalence was reported in Japanese than in the Western population. ${ }^{7}$

It inflicts significant impact on quality of life of patients, interfering with their labor, daily activities, social interaction and leisure, and can cause emotional and psychological distress. ${ }^{7-10}$
The natural history of palmar hyperhidrosis is the onset of excessive sweating in childhood for mostly individuals, manifesting itself more strongly in ages of hormonal and sexual maturation during adolescence. Improvement after the fourth decade of life is common, and cases that persist after the fifth decade of life are rare. $^{11-15}$

There seems to be a genetic predisposition to $\mathrm{PH}$, evidenced by family transmission through autosomal dominant genes. ${ }^{16}$ The 14q11.2-q13 locus was identified as associated with palmar hyperhidrosis in Japaneses. ${ }^{17}$

Symptoms are usually bilateral and symmetrical and there are no other associated conditions. Palms are cold, wet and present color that can ranges from pale to blush. The episode of sweating has abrupt onset, related or not with emotional stressful events, and presents more intensely on the palms and fingers and less intensely in the posterior regions of the hands. Rapidly, the hands are wet by the droplet detachment, and in some cases there may be swelling of the fingers (Figure 1). ${ }^{12,13,15-20}$

In this article, a literature review was performed in the main databases available (PUBMED, EMBASE, MEDLINE, SCIELO) on clinical, pathophysiological, diagnostic and therapeutic related to palmar hyperhidrosis.

Received on 10.11.2015.

Approved by the Advisory Board and accepted for publication on 16.12.2015.

* Study performed at Departamentos de Dermatologia e de Cirurgia da Faculdade de Medicina de Botucatu - Universidade Estadual Paulista “Júlio de Mesquita Filho" (FMB-Unesp) - Botucatu (SP), Brazil.

Financial support: none.

Conflict of interest: none.

Universidade Estadual Paulista “Júlio de Mesquita Filho" (Unesp) - Botucatu (SP), Brazil.

(C2016 by Anais Brasileiros de Dermatologia 


\section{PATHOPHYSIOLOGY OF PALMAR HYPERHIDROSIS}

The human body has about 4 million sweat glands, of which $75 \%$ are eccrine. The eccrine sweat glands are epidermal appendages innervated by cholinergic fibers of the sympathetic nervous system, whose main function is to produce sweat, which is odorless, colorless, and responsible for regulating the body temperature. They are present throughout the body surface, predominantly in the palmar, plantar, axillary and craniofacial regions. ${ }^{21-26}$

Each gland has a secretory portion composed of a spiral of cuboidal cells in the deep dermis, whose excretory duct is directed into the epidermis and through an opening in the surface (Figure 2). Eccrine glands exhibit as exuberant capillary plexus at its base.

The eccrine secretion is achieved through displacement of calcium ions from the extracellular environment to the interior of the secreting cell, controlling the stimulation and activation of ions and water in this environment. The sweat consists mainly of sodium chloride, water, 2-methylphenol, 4-methylphenol, urea and other nitrogen metabolites, resulting in a hypotonic secretion in relation to plasma. ${ }^{25-27}$

Apocrine sweat glands are limited to the axillary and urogenital regions. They are also called scent glands and do not participate in localized hyperhidrosis, and its activation is regulated by hormonal processes. Apoecrine glands have also been described in the armpits. ${ }^{27-29}$

No histopathological finding was identified in individuals with palmar hyperhidrosis, nor the increase in the amount of sweat

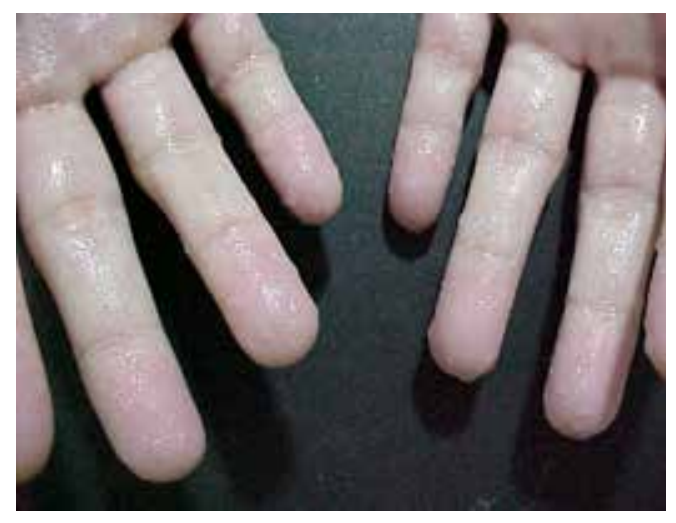

Figure 1:

Palmar hyperhidrosis. Spon$\mathrm{t}$ a n e o u s $\mathrm{s}$ w e a $\mathrm{t}$ dripping in both hands, without relation with the need to control body temperature

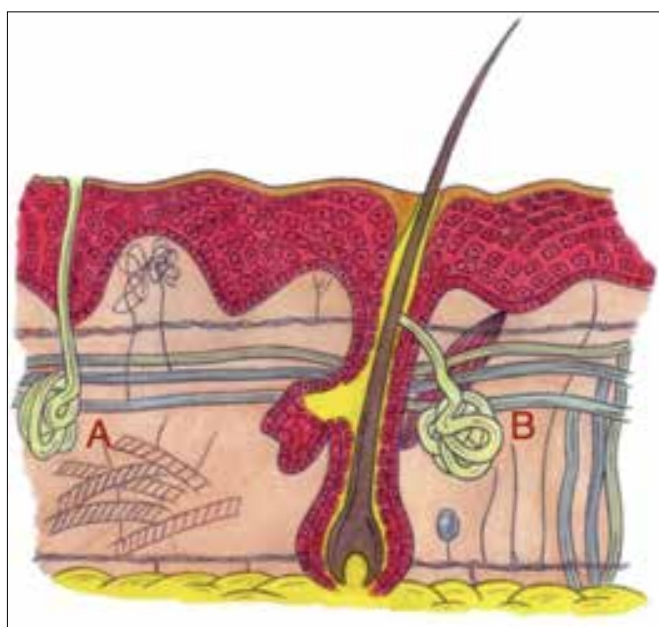

Figure 2:

$\mathrm{Sc}$ h e $\mathrm{m}$ e of the histological aspect of e c c r i n e (A) and a pocrine (B) sweat glands, and their relation to the skin structure

S o u r c e : Romero et al., 2015. ${ }^{63}$ glands. This data suggests that there is a complex disorder of the autonomic nervous system involving the sympathetic and parasympathetic pathways, and it can be inferred that $\mathrm{PH}$ is primarily a neurological disease with exuberant cutaneous manifestation..$^{19,26}$

Sympathetic activity in a particular part of the body can be estimated by measuring the skin resistance to electrical conduction, an indirect measure of sudomotor function. Electrophysiological studies show high skin sympathetic response in patients with palmar hyperhidrosis compared with healthy subjects. ${ }^{19,26,27}$

Sympathetic motor pathway consists of three neurons (Figure 3). The first neuron has its cell body located in sudomotor nerve centers and hypothalamic vasomotor and its axon is moving downwards by dorsal longitudinal and spinal vestibular fascicles of the spinal cord, causing synapse with the second neuron.

The second neuron is the preganglionic, located in the itermediolateral column of the spinal cord gray matter (Clarke's column), which extends from the first lumbar to the second lumbar segment of spinal cord. Its axon leaves the cord by the white ramus communicans, along with the ventral roots of the spinal nerves, and heads for the paravertebral ganglia of the sympathetic trunk, making synapses with the third neuron.

The third neuron (postganglionic) leaves the sympathetic chain by gray ramus communicans and joins the spinal nerve, distributing peripherally to the sweat glands. ${ }^{27}$

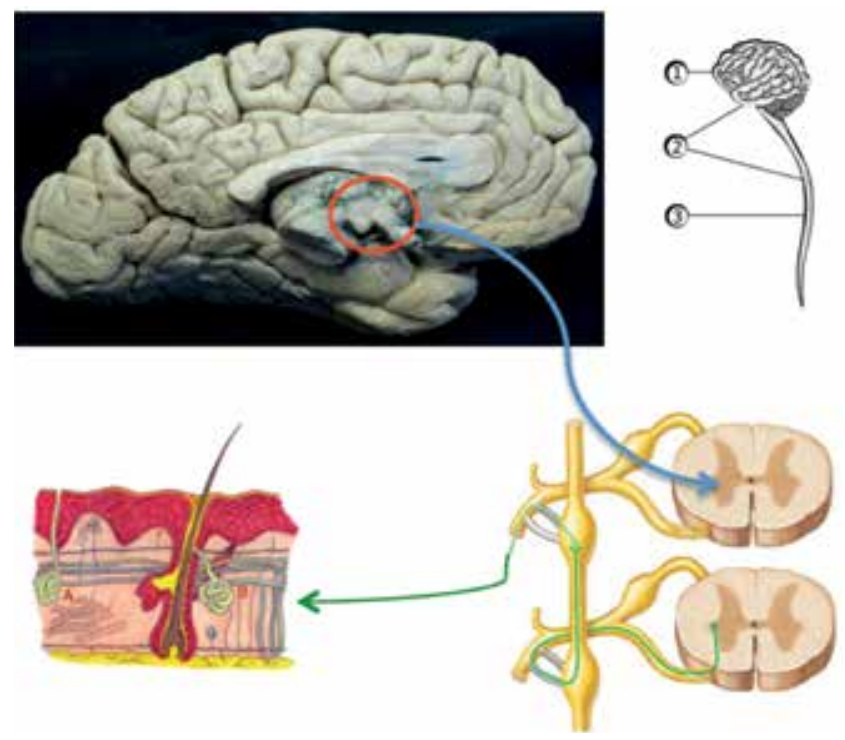

FIGURE 3: Scheme of the sympathetic pathway of sweat control. Top left image shows the region where the hypothalamus is located, in parasagittal section of anatomical specimen (red circle). Top right image shows the relation between the brain (1) and the cervical and thoracic spinal cords (2) and lumbar (3). The blue arrow represents the location of the synapse between the first neuron and the second neuron of the pathway in Clarke's column of the thoracic spine. Lower right image is an axial section of cord, with the area of the synapse between the second and third neurons located in the ganglion of the sympathetic chain (green line). The green arrow represents the third neuron, which triggers the stimulus on the sweat glands by the acetylcholine neurotransmitter. Bottom left image shows the scheme of the histological structures of the skin and its relation with the eccrine (A) and apocrine (B) sweat glands

Source: Romero et al., 2015. ${ }^{63}$ 
The sympathetic ganglia are distributed longitudinally on each side of the spine and are connected by interganglionar pathways. Usually, three cervical ganglia (upper, middle and lower), ten to twelve thoracic, two to five lumbar, four to five sacral, and one at coccyx, are identified..$^{27}$

The craniocervical region is innervated by preganglionic sudomotor fibers originating from the first to the fifth segment of the thoracic spine. Moreover, sudomotor fibers of the upper limb originate from the second to the eighth segments; and those of the lower limbs from the tenth thoracic segment to the second lumbar segment. 27,28

The main neurotransmitter of the neuroglandular junction of postganglionic fibers is the acetylcholine, unlike what happens in most of the nerve endings, whose neurotransmitter is the noradrenaline. Various stimuli, such as physical activity, hot environment, anxiety and stress, activate the preoptic area of the hypothalamus that, by sympathetic stimulation, release acetylcholine in the neuroglandular junction, increasing the response in the sweat gland and generating a retrograde stimulus to the hypothalamus through the afferents pathways, the negative feedback. The balance between the afferent and efferent pathways maintains homeostasis in the body. In individuals with $\mathrm{PH}$, this system appears to be in focal imbalance, with amplification of efferent stimuli. ${ }^{27,28}$

\section{PALMAR HYPERHIDROSIS DIAGNOSIS}

The $\mathrm{PH}$ diagnosis is eminently clinical, being conducted through history and physical examination. Individuals with palmar hyperhidrosis present cold and wet hands with color that can ranges from pale to blush. ${ }^{29-33}$ Plantar hyperhidrosis often (57\% of cases) is associated with palmar hyperhidrosis, being described by some authors as part of the symptomatology of these individuals. ${ }^{1,15,19,22}$

The main diagnostic criteria include visible sweat, exaggerated and located, lasting at least six months, without apparent cause, and with at least two of the following characteristics: ${ }^{19}$

- Bilateral and symmetrical sweat

- Frequency: at least one episode per week

- Impairment in daily activities

- Age of the onset $<25$ years

- Presence of family history

- Absence of sweat during sleep

$\mathrm{PH}$ can be evidenced from the Minor test (starch-iodine), in which an alcoholic solution of iodine $2 \%$ is applied in the test area and subsequently starch (e.g. cornstarch) is sprinkled. The hyperhidrotic area solubilizes the iodine, which promotes a complexation reaction with the starch. As the iodine atoms are trapped in the helices of amylose chains, there is evidence of a dark blue staining (Figure 4). ${ }^{20}$

For research purposes, the absorptiometry of sweating can be measured by paper filter technique and gravimetry. However, these techniques are difficult to reproduce in clinical practice because they need to be performed in an environment with controlled pressure and temperature. ${ }^{31}$

\section{DIFFERENTIAL DIAGNOSIS}

The body's thermoregulation is dependent on the sweating mechanism. In certain physiological conditions, we can observe hy- peractivity of the sweat glands, such as during and after exercise, in obese people, and in menopause.

However, it is mandatory the differential diagnosis with associated conditions, which consist of the cases of secondary hyperhidrosis. The main associated conditions are: ${ }^{12,15,19}$

- Endocrine: hyperthyroidism, hypopituitarism, diabetes, menopause, hypoglycemia, pregnancy, pheochromocytoma, carcinoid syndrome and acromegaly.

- Neurologic: Parkinson's disease, spinal cord injury and stroke, vasovagal syndrome, hypothalamic hyperhidrosis, reflex sympathetic dystrophy.

- Neoplastic: tumors of the central nervous system (CNS), Hodgkin's disease and myeloproliferative diseases, cancer of the thoracic cavity.

- Infectious: feverish conditions, tuberculosis and septicemia.

- Drugs: fluoxetine, venlafaxine, doxepin, opioids, amitriptyline, insulin, nonsteroidal anti-inflammatory.

- Toxicity: alcoholism and substance abuse.

- Iatrogenic: postoperative compensatory sweating (sympathectomy, cardiac surgery).

All of the above conditions, except spinal cord damage and reflex sympathetic dystrophy, cause diffuse sweating (secondary generalized hyperhidrosis), in contrast to $\mathrm{PH}$, which are located. ${ }^{1,3,19}$

\section{QUALITY OF LIFE IN PALMAR HYPERHIDROSIS}

The concept of quality of life (QoL) has been discussed since 1970. In the 1980s, Cohen built a reflection on QoL from the discussions in performing coronary artery surgery. According to the author, human life is a sine qua non condition for human values, showing a fundamental relation between the biological living being and its subjective condition. ${ }^{34,35}$

Because of this subjectivity and a few discussions on the issue until the 1980s, the term QoL was used synonymously with life satisfaction, self-esteem, happiness, well-being, health, value and meaning of life, functional independence and ability to take care of oneself. The assessment of QoL has multiple dimensions and is influenced by many factors related to health and non-medical di-

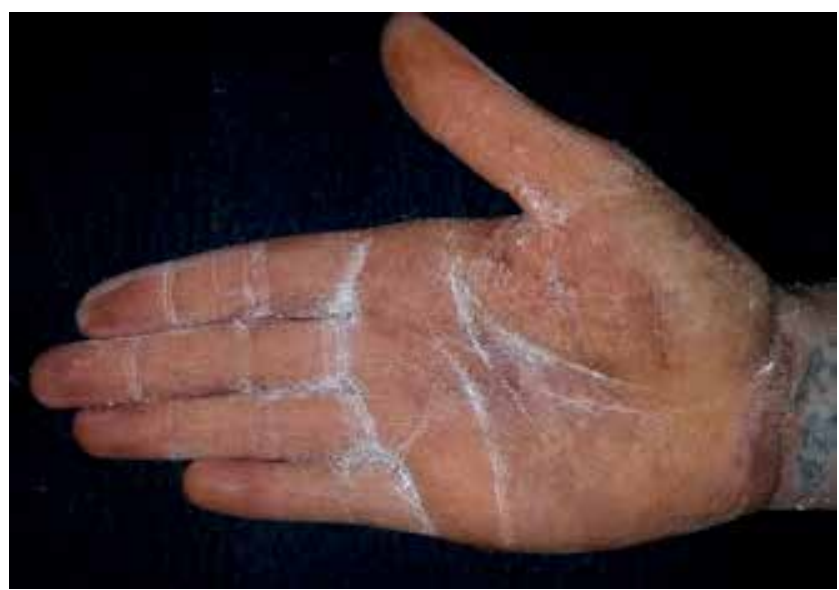

FIGURE 4: Minor test (starch-iodine). Complexation reaction between iodine and amylose, precipitated by sweat. It allows the identification of areas of increased sweating 
mensions, such as education, economic and socio-cultural aspects. There is no consensus on its definition, but most authors agree that physical, social, psychological and spiritual domains should be observed, seeking to capture each individual's personal experience. Marital status, success in the profession, joy, ambition, personality, expectations and faith also must be addressed..$^{34-36}$

Questionnaires specific on QoL are outcomes usually used to evaluate the effectiveness of therapeutic in $\mathrm{PH}$. Below are the main validated questionnaires on evaluation of severity and QoL for palmar hyperhidrosis and used in clinical trials:

- Hyperhidrosis Disease Severity Scale (HDSS): specific for this disorder, it provides a qualitative measure of the severity of the patient $>$ s condition based on its way to affect daily activities. The patient selects the statement that best reflects his/her experience with sweating in each area evaluated. This is a practical diagnostic tool, simple and easy to understand, which can be administered quickly and shows good correlation with other survey modes. Improvement of one point on this scale was associated with a $50 \%$ reduction in sweat production, and two points, with an $80 \%$ reduction. ${ }^{37}$

- Dermatology Life Quality Index (DLQI): it was first developed in 1994, with ten simple questions to assess 40 different skin diseases and their impact on QoL of patients. It received an adaptation for cases of hyperhidrosis, being a simple tool to be applied. ${ }^{38}$

- Keller questionnaire (Keller): specific questionnaire for hyperhidrosis that evaluates the social, emotional, work and daily activities conditions, including symptoms related to plantar hyperhidrosis. It consists of fifteen questions which considers the «stress level», scoring from 0 (none) to 10 (worst possible) various situations of everyday life. Score above 100 is indicative of serious cases and, above 125 , very serious. ${ }^{39}$

- Campos Questionnaire (Campos): developed specifically to evaluate the results of sympathectomy by thoracoscopy in the treatment of palmar hyperhidrosis. It considers the overall impression of hyperhidrosis for the individual, functional, social, personal, emotional own impression and with others and special conditions. The questionnaire punctuates these parameters from 1 (very good) to 5 (very bad). Before surgery scores between 20 and 35 are excellent; 36 and 52 , very good; 53 and 68 , good; 69 and 84 , bad; and over 85 , very bad. After surgery, scores between 20 and 35 are considered as much better condition; between 36 and 52, better; 53 and 68, the same; 69 and 84 , a little worse; and above 85 , much worse. ${ }^{1}$

\section{PALMAR HYPERHIDROSIS TREATMENT}

$\mathrm{PH}$ does not compromise physical health. Nevertheless, the treatment aims to reduce the impact of disease on patients' QoL.

\section{Clinical treatment}

Clinical treatment may be topical or systemic. ${ }^{40-45}$ Among the topical treatment options, we highlight the use of astringents, iontophoresis and botulinum toxin. Systemic treatment consists of the administration of anticholinergic drugs and psychotherapy. ${ }^{43-45}$ In addition, some new therapeutic methods have been described in recent years. ${ }^{46-51}$

- Astringent solutions: also called antiperspirants, they act on the opening of the sweat glands blocking the elimination of sweat. They are indicated for palmar and axillary hyperhidrosis of mild to moderate intensity. The most widely used is the aqueous solution of aluminum chloride $20-30 \%$, which should be applied preferably during night, two to three times a week. The main undesirable events observed are redness and skin irritation. ${ }^{15,48}$ The tannic acid in solution 2-5\% was reported as effective in mild cases.

- Iontophoresis: immersion of affected area in ionized solution with electric current of low voltage. It is suggested that ionic changes on the sweat glands cause temporary blockage of sweating, with improvement in symptoms for about four weeks. The major limitation of this method is the frequency of treatment, which should be from 30 to 40 minutes, daily, on the affected area, at least four times a week. ${ }^{48-52}$

- Anticholinergic drugs: they act as antagonists of muscarinic receptors of the sweat glands, competing with acetylcholine. The oxybutynin hydrochloride $5-10 \mathrm{mg} /$ day is one of the most used, with results considered promising. The effectiveness is dose-dependent, and often the adverse events are well tolerated, such as dry mouth, urinary retention, intestinal constipation, postural hypotension, dyspepsia, nausea and vomiting. Furthermore, it should not be used in patients with glaucoma. ${ }^{48,51}$ In addition to systemic anticholinergic medications, it has been described the use of topical agents such as glycopyrrolate $0.5 \%$ to $2 \%$, which has the advantage of reducing the systemic adverse events of the anticholinergic drugs, being effective in some studies. ${ }^{49,51}$

- Botulinum toxin: it blocks the release of acetylcholine in neuroglandular junction, resulting in decreased impulse transmitted to the sweat gland. The symptoms resolution is maintained by about 6 months, requiring repeated applications. A disadvantage of this method is the painful condition that occurs during the application in some areas of the body, such as hands and feet. In addition, it may be associated with reduced hypothenar muscle strength. The best indication is for individuals with pure axillary hyperhidrosis, as motor abnormalities in this region do not cause functional damage. ${ }^{48,51}$ Isolated reports showed success of botulinum toxin conveyed by iontophoresis and phonophoresis, but controlled studies with long follow-up are needed to define the scope of these therapeutic modalities. ${ }^{48,49}$

- Psychotherapy: it aims to control anxiety and insecurity, with consequent reduction of cortical stimulation to the autonomic nervous system. Adolescence is characterized by conflicts and difficulties of coping, and represents the stage with the highest incidence and impact of the disease, which strengthens the role of psychotherapy to approach the patients with $\mathrm{PH} .{ }^{48,51}$

- Emerging therapies: fractional radiofrequency with microneedles, microwave therapy and use of high intensity focused ultrasound (HIFU). We need more studies to assess their efficacy and safety. ${ }^{50,51}$

\section{Surgical treatment}

Currently, the video-assisted thoracoscopic sympathectomy (VATS) is considered the most effective treatment for PH for presenting long lasting functional results, being considered the best therapeutic option. ${ }^{53,54}$

Until the late 1980s, the term sympathectomy was defined 
as resection of the sympathetic chain, including the target ganglion. With the advent of VATS, the term came to be used only for the transection of the sympathetic chain above and below the selected ganglion or only its electrical cauterization (Figure 5). ${ }^{31-33}$

Kopelman and Hashmonai reviewed the main techniques used in the treatment of palmar hyperhidrosis between 1990 and 2006 and identified 42 different techniques for the sympathetic ganglion approach. ${ }^{40}$ When exclusion criteria were applied, only 23 techniques remained, the main ones being: resection, cauterization, chain transection, ramicotomy and sympathetic chain clipping.

Several surgical approaches have been used to perform the sympathectomy, among which we highlight the posterior thoracic, anterior cervical or supraclavicular and axillary pathways. ${ }^{31-33} \mathrm{How}-$ ever, due to the high rate of morbidity and mortality, these accesses were abandoned after the emergence of VATS. ${ }^{31}$

The main adverse event found in this procedure is compensatory hyperhidrosis $(\mathrm{CH})$. It occurs in a variable percentage of $10 \%$ to $40 \%$ of the series, but a small number of patients (5\%), usually submitted to interruption of the chain of the second ganglion level, suffers from a more severe form. . $, 7,18^{2}$

Shoenfeld suggested that the total amount of sweat did not change after sympathectomy and increased sweating in other parts of the body would represent a compensation of the organism in response to the procedure, naming it as $\mathrm{CH} .{ }^{53}$

Although the exact mechanism of $\mathrm{CH}$ remains unknown, there is a hypothesis to occur as a reflex mediated by the hypothalamus after the procedure on the sympathetic chain. ${ }^{32,33}$ Some authors believe that sweating after sympathectomy would be a reflex phenomenon mediated by a autoregulation mechanism among the hypothalamus, body thermoreceptors and sweat glands, or by the failure of the feedback mechanism in the sectioned chain. ${ }^{33,54}$
Before sympathectomy, the temperature would influence the thermoreceptors in the skin, triggering a stimulus to the thermoregulatory center of the hypothalamus. The efferent fibers, responsible for the positive stimulus, would transmit the impulse generated in the hypothalamus to the sympathetic ganglia, which in turn would generate a positive response to the sweat. ${ }^{33,34,54}$ After this event, an afferent response to the hypothalamus occur, responsible for a negative stimulus. ${ }^{32,33,34,54}$

When the lesion of the thoracic ganglia T2, T3 and T4 is performed, the efferent stimulus transmitted to sympathetic ganglia would be amplified to the periphery by the loss of the negative stimulus to the hypothalamus by afferent pathways. Because the amplified stimuli do not reach the sympathectomized areas, there may be increased sweating in other regions. ${ }^{33,34,54}$

There seems to be a correlation between the severity of $\mathrm{CH}$ and the extension of resection, as the ganglion approached in the procedure. ${ }^{31-34,54}$ When the lesion is performed at the T2 ganglion, there is a total interruption of the afferent negative stimulus to the hypothalamus, favoring the emergence of $\mathrm{CH}$ on the periphery by the amplification of the positive efferent stimuli released by the preoptic area of the hypothalamus. But when the lesion is performed at the T4 ganglion, most negative afferent fibers is preserved, and the positive efferent stimulation is less intense, occurring no severe cases of $\mathrm{CH}^{33,34,54}$

\section{Radiofrequency sympathectomy}

The radiofrequency thoracic sympathectomy was first described by Wilkinson in 1984 as a novel technique for the treatment of pain syndromes. ${ }^{55,56}$ In subsequent years, the procedure was dropped, returning to be used in the mid-2000s, in selected cases of neuropathic pain in the upper limbs, such as complex regional

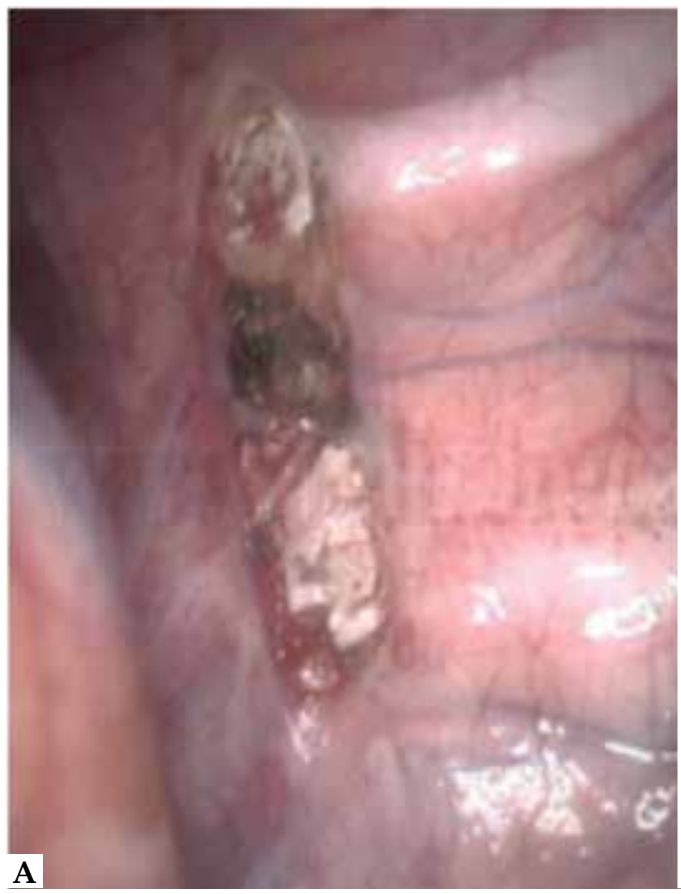

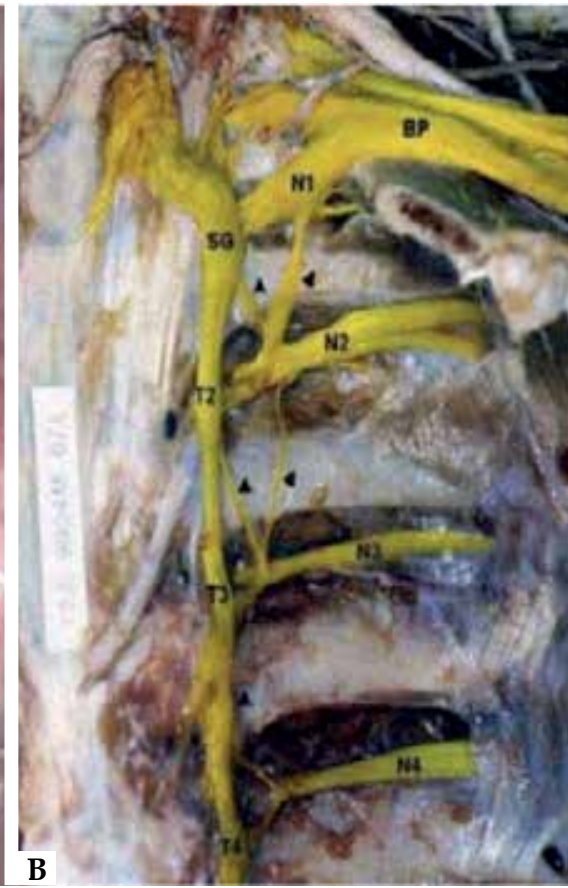

FIGURE 5: Intraoperative image of video-assisted thoracoscopic sympathectomy (A). Scheme of the anatomical relations of the thoracic sympathetic trunk (B)

Source: Romero et al., 2015. ${ }^{63}$ 

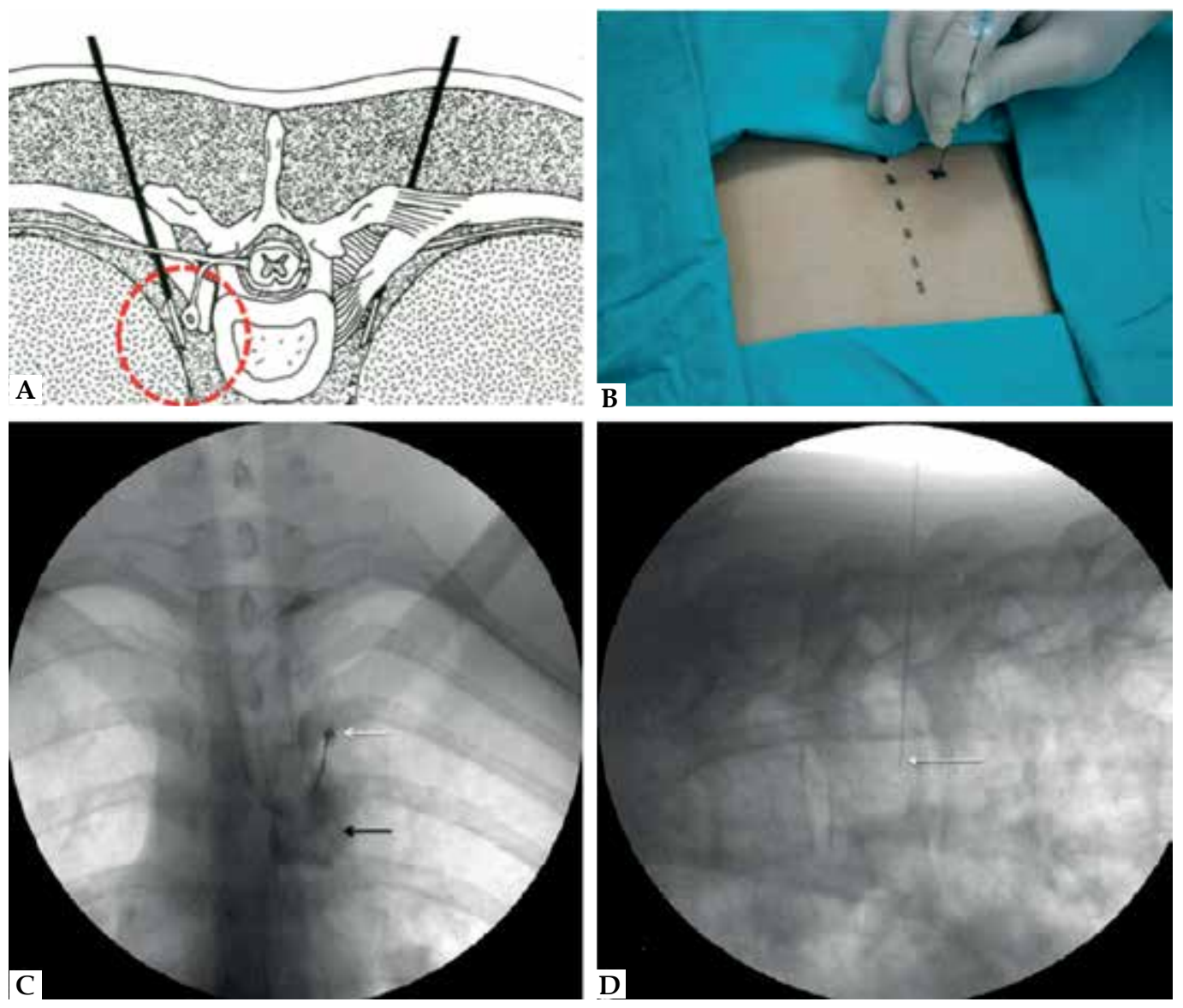

Figure 6:

Example of percutaneous thoracic sympathectomy in the T4 ganglion. A. Illustration of proper needle position, parallel to the ganglion of the thoracic chain. B. Positioning the needle in the skin for beginning of puncture. $\mathrm{C}$. Anteroposterior view of fluoroscopic showing the proper position of the needle (white arrow) above the head of the rib (black arrow). D. View in profile of fluoroscopy showing the correct position of the needle (white arrow)

Source: Romero et al., 2015. ${ }^{63}$

pain syndrome and phantom limb syndrome. ${ }^{57-60}$ Few reports of this procedure are found in the literature for the treatment of palmar hyperhidrosis. ${ }^{61}$

It consists of minimally invasive procedure, percutaneous, performed under local anesthesia and mild sedation, which uses puncturing techniques guided by fluoroscopy to locate an electrode near the thoracic sympathetic chain and perform the thermal ablation of these structures. ${ }^{55-56}$ It is usually performed in outpatient clinics or day-hospital regimens, with low morbidity and satisfactory results in the control of pain syndromes (Figure 6). ${ }^{55,56,61,62}$

The main complications include pain and bruising at the puncture site, chest pain, pneumothorax, vascular lesions near the thoracic chain and Horner's syndrome. Typically, the post-procedural pain is easily controlled with analgesics and Horner's syndrome regresses in most cases. But pneumothorax and vascular lesions are the most feared complications, requiring chest drainage described in some cases. ${ }^{55-60}$

In a recent study performed at Unesp Medical School (Botucatu, SP, Brazil), involving 36 patients with palmar hyperhidrosis who underwent percutaneous radiofrequency upper thoracic sympathectomy (T4) with follow-up of 2 years, it was observed that the procedure presented a positive impact on the QoL of individuals with palmar hyperhidrosis, with low rate and intensity of $\mathrm{CH}$ and recurrence, and zero morbidity and mortality. In addition, there was a high degree of satisfaction in $83 \%$ of patients. ${ }^{63}$

Portuloglu et al. had a $75 \%$ success rate in a percutaneous technique and $95 \%$ rate in a video-assisted thoracoscopy technique. ${ }^{62}$ Fouad obtained a rate of $90 \%$ improvement in sweating in his series of ten cases submitted to T2 ganglion lesion. ${ }^{64}$

When the advantages of the percutaneous procedure are analyzed in relation to thoracoscopy, it is observed that it is a minimally invasive procedure performed with one day hospitalization and local anesthesia with mild sedation, short time between the procedure and discharge, low morbidity and virtually zero mortality. In addition, the time to return to daily activities is early. ${ }^{62-64}$

Prospective clinical trials, compared with VATS and with long follow-up, should define the role of percutaneous radiofrequency sympathectomy in the treatment of palmar hyperhidrosis.

\section{CONCLUSION}

Palmar hyperhidrosis is a condition that has important consequences on the quality of life of individuals, causing social embarrassment and difficulties in school and professional environments. There are a variety of treatments available and the individual choice of the best option for each patient can help in improving their quality of life.] 


\section{REFERENCES}

1. de Campos JR, Kauffman P, Werebe Ede C, Andrade Filho LO, Kusniek S, Wolosker $\mathrm{N}$, et al. Quality of life, before and after thoracic sympathectomy: report on 378 operated patients. Ann Thorac Surg. 2003;76:886-91.

2. Hornberger J, Grimes K, Naumann M, Glaser DA, Lowe NJ, Naver H, et al. Recognition, diagnosis and treatment of primary focal hyperhidrosis. J Am Acad Dermatol. 2004:51:274-86.

3. Eisenach JH, Atkinson JL, Fealey RD. Hyperhidrosis: evolving therapies for a wellestablished phenomenon. Mayo Clin Proc. 2005;80:657-66.

4. Wörle B, Rapprich S, Heckmann M. Definition and treatment of primary hyperhidrosis. J Dtsch Dermatol Ges. 2007;5:625-8.

5. Vetrugno R, Liguori R, Cortelli P, Montagna P. Sympathetic skin response: basical mechanisms and clinical applications. Clin Auton Res. 2003;13:256-70.

6. Karimian-Teherani D, Panhofer P, Ringhofer C, Jakesz R, Prager M, Zacherl J, et al New epidemiological aspects of patients with severe hyperhidrosis presenting for sympathetic surgery. J Eur Acad Dermatol Venereol. 2009;23:651-5.

7. Cloward RB. Treatment of hyperhidrosis palmaris (sweaty hands); a familial disease in Japanese. Hawaii Med J. 1957:16:381-7.

8. Amir M, Arish A, Weinstein Y, Pfeffer M, Levy Y. Impairment in quality of life among patients seeking surgery for hyperhidrosis (excessive sweating): preliminary results. Isr J Psychiatry Relat Sci. 2000;37:25-31.

9. Lerer B, Jacobowitz J, Wahba A. Personality features in essential hyperhidrosis. Int J Psychiatry Med. 1980-1981;10:59-67.

10. Leão LE, de Oliveira R, Szulc R, Mari Jde J, Crotti PL, Gonçalves JJ. Role of videoassisted thoracoscopic sympathectomy in the treatment of primary hyperhidrosis. Sao Paulo Med J. 2003;121:191-7

11. Strutton DR, Kowalski JW, Glaser DA, Stang PE. US prevalence of hyperhidrosis and impact on individuals with axillary hyperhidrosis: results from a national survey. J Am Acad Dermatol. 2004:51:241-8.

12. Leung AK, Chan PY, Choi MC. Hyperhidrosis. Int J Dermatol. 1999;38:561-7.

13. Lear W, Kessler E, Solish N, Glaser DA. An epidemiological study of hyperhidrosis. Dermatol Surg. 2007;33:S69-75.

14. Gee S, Yamauchi PS. Nonsurgical management of hyperhidrosis. Thorac Surg Clin. 2008:18:141-55

15. Murray CA, Cohen JL, Solish N. Treatment of focal hyperhidrosis. J Cutan Med Surg. 2007;11:67-77.

16. Ro KM, Cantor RM, Lange KL, Ahn SS. Palmar hyperhidrosis: evidence of genetic transmission. J Vasc Surg. 2002:35:382-6.

17. Higashimoto I, Yoshiura K, Hirakawa N, Higashimoto K, Soejima H, Totoki T, et al Primary palmar hyperhidrosis locus maps to $14 q 11.2-q 13$. Am J Med Genet A. 2006;140:567-72

18. Kim WO, Kil HK, Yoon KB, Yoon DM, Lee JS. Influence of T3 or T4 sympathicotomy for palmar hyperhidrosis. Am J Surg. 2010;199:166-9.

19. Haider A, Solish N. Focal hyperhidrosis: diagnosis and management. CMAJ. 2005;172:69-75

20. Muller SA, Kierland RR. The use of a modified starch-iodine test for investigating local sweating responses to intradermal injection of methacholine. J Invest Dermatol. 1959;32:126-8.

21. Togel B, Greve B, Raulin C. Current therapeutic strategies for hyperhidrosis: a review. Eur J Dermatol. 2002;12:219-23.

22. Ackerknecht EH. The history of the discovery of the vegetative (autonomic) nervous system. Med Hist. 1974;18:1-8.

23. Langley JN. On axon-reflexes in the pre-ganglionic fibers of the sympathetic system. J Physiol. 1900;25:364-98.

24. Eccles JC. The action potential of the superior cervical ganglion. J Physiol. 1900;25:364-98

25. Eccles JC. Facilitation and inhibition in the superior cervical ganglion. J Physiol 1935:85:207-238.3.

26. Kirstein SL, Insel PA. Autonomic nervous system pharmacogenomics: a progress report. Pharmacol Rev. 2004:56:31-52.

27. Junqueira LC, Carneiro J. Tecido nervoso. In: Junqueira LC, Carneiro J. Histologia básica. 9. ed. Rio de Janeiro: Guanabara Koogan; 1999. p.129-58.

28. Machado ABM. Sistema nervoso autônomo: aspectos gerais. In: Machado ABM Neuroanatomia funcional. 2. ed. São Paulo: Atheneu; 1998. p.129-38.

29. Machado ABM. Sistema nervoso autônomo: anatomia do simpático parassimpático e dos plexos viscerais. In: Machado ABM. Neuroanatomia funcional. 2. ed. São Paulo: Atheneu; 1998. p.139-50.

30. Kauffman P, Cinelli M Jr, Wolosker M, Leão LE. Treatment of palmar hyperhidrosis by cervico-thoracic sympathectomy. AMB Rev Assoc Med Bras. 1978;24:29-30.

31. Serup J, Jemec GBE. Methods for the collection of eccrine sweat. In: Serup J, Jemec GBE, editors. Handbook of Non-Invasive Methods and the Skin. 2nd ed. Florida: CRC Press, Boca Raton;1995. p.817-820.
32. White JW Jr. Treatment of primary hyperhidrosis. Mayo Clin Proc. 1986;61:951-6.

33. Campos JR, Kauffman P. Video-assisted thoracic sympathectomy in the treatment of primary hyperhidrosis. J Bras Pneumol. 2007;33:15-7.

34. Cohen C. On the quality of life: some philosophical reflections. Circulation. 1982;66:29-33

35. Cohen SR, Mount BM, MacDonald N. Defining quality of life. Eur J Cancer 1996:32A:753-4.

36. Pinto-Neto AM, Conde DM. Qualidade de vida. Rev Bras Ginecol Obstet. 2008;30:535-6.

37. Johnson JE, O'Shaughnessy KF, Kim S. Microwave thermolysis of sweat glands. Lasers Surg Med. 2012;44:20-5.

38. Finlay AY, Khan GK. Dermatology Life Quality Index (DLQI): A simple practical measure for routine clinical use. Clin Exp Dermatol. 1994;19:210-6.

39. Leão LE, de Oliveira R, Szulc R, Mari Jde J, Crotti PL, Gonçalves JJ. Role of vídeoassited thoracoscopy sympathectomy in the treatment of primary hyperhidrosis. Sao Paulo Med J. 2003;121:191-7.

40. Krasna MJ. Thorachoscopic sympathectomy: a standardized approach to therapy for hyperhidrosis. Ann Thorac Surg. 2008;85:S764-7.

41. Kopelman D, Hashmonai M, Schick C. The surgical treatment of hyperhidrosis. Ann Thorac Surg. 2012;93:1021-2

42. Bovell DL, Clunes MT, Elder HY, Milsom J, Jenkinson DM. Ultrastructure of the hyperhidrotic eccrine sweat gland. Br J Dermatol. 2001:145:298-301.

43. James WD, Schoomaker EB, Rodman OG. Emotional eccrine sweating. A heritable disorder. Arch Dermatol. 1987;123:925-9.

44. Solish N, Bertucci V, Dansereau A, Hong HC, Lynde C, Lupin M, et al. A comprehensive approach to the recognition, diagnosis, and severity- based treatment of focal hyperhidrosis: Recommendations of the Canadian Hyperhidrosis Advisory Committee. Dermatol Surg. 2007;33:908-23

45. Cohen JL, Cohen G, Solish N, Murray CA. Diagnosis, impact, and management of focal hyperhidrosis: Treatment review including botulinum toxin therapy. Facial Plast Surg Clin North Am. 2007:15:17-30, v-vi.

46. Solish N, Wang R, Murray CA. Evaluating the patient presenting with hyperhidrosis. Thorac Surg Clin. 2008:18:133-140.

47. Ojimba TA, Cameron AE. Drawbacks of endoscopic thoracic sympathectomy. $\mathrm{Br}$ J Surg. 2004;91:264-9.

48. Andrade PC, Flores GP, Uscello Jde F, Miot HA, Morsoleto MJ. Use of iontophoresis or phonophoresis for delivering on a botulinum toxinA in the treatment of palmar hyperidrosis: a report on four cases. An Bras Dermatol. 2011;86:1243-6.

49. Connolly M, de Berker D. Management of primary hyperhidrosis: a summary of the different treatment modilities. Am J Clin Dermatol. 2003;4:681-97.

50. Prerovsky K. On iontophoresis. Prakt Lek. 1953;33:247-9.

51. Rajagopal R, Mallya NB. Comparative evaluation of botulinum toxin versus iontophoresis with topical aluminium chloride hexahydrate in treatment of palmar hyperhidrosis. Med J Armed Forces India. 2014;70:247-52.

52. Pieretti LJ. Resources for hyperhidrosis sufferers, patients, and health care providers. Dermatol Clin. 2014;32:555-64.

53. Pariser DM, Ballard A. Iontophoresis for palmar and plantar hyperhidrosis. Dermatol Clin. 2014;32:491-4

54. Shoenfeld Y, Shapiro Y, Machtiger A, Magazanik A. Sweat studies in hyperhidrosis palmaris and plantaris. A survey of 60 patients before and after cervical sympathectomy. Dermatologica. 1976;152:257-62.

55. Rodríguez PM, Freixinet JL, Hussein M, Valencia JM, Gil RM, Herrero J,et al. Side effects, complications and outcome of thoracoscopic sympathectomy for palmar and axillary hyperhidrosis in 406 patients. Eur J Cardiothorac Surg. 2008:34:514-9.

56. Wilkinson HA. Percutaneous radiofrequency upper thoracic sympathectomy: a new technique. Neurosurgery. 1984;15:811-4.

57. Wilkinson HA. Radiofrequency percutaneous upper-thoracic sympathectomy. Technique and review of indications. N Engl J Med. 1984;311:34-6.

58. Wilkinson HA. Percutaneous radiofrequency upper thoracic sympathectomy. Neurosurgery. 1996;38:715-25.

59. Garcia Franco CE, Perez-Cajaraville J, Guillen-Grima F, España A. Percutaneous radiofrequency sympathicolysis versus surgical standard procedure. Eur $J$ Cardiothorac Surg. 2014;45:1118.

60. Purtuloğlu T, Deniz S, Atım A, Tekindur Ş, Gürkök S, Kurt E. A new target of percutaneus sympathic radiofrequency thermocoagulation for treatment of palmar hyperhidrosis: T4. Agri. 2013;25:36-40.

61. Racz GB, Stanton-Hicks M. Lumbar and thoracic sympathetic radiofrequency lesioning in complex regional pain syndrome. Pain Pract. 2002;2:250-6.

62. Purtuloglu T, Atim A, Deniz S, Kavakli K, Sapmaz E, Gurkok S, et al. Effect of radiofrequency ablation and comparison with surgical sympathectomy in palmar hyperhidrosis. Eur J Cardiothorac Surg. 2013;43:e151-4 
63. Romero FR. The impact of high thoracic percutaneous simpathectomy with radiofrequency in quality of life among patients with palmar hyperhidrosis [thesis]. Botucatu (SP): Botucatu Medical School, Universidade Estadual Paulista; 2015. $127 f$.

64. Fouad W. Management of essencial hyperhidrosis of upper limbs by radiofrequency thermocoagulation of second thoracic ganglion. Alexandria Journal of Medicine. 2011;47:193-9.
MAILING ADDRESS:

Hélio Amante Miot

Departamento de Dermatologia - Unesp - Botucatu

Distrito de Rubião Júnior, $s / n$

18618-970 - Botucatu - SP

Brazil

Email: heliomiot@fmb.unesp.br

How to cite this article: Romero FR, Haddad GR, Miot HA, Cataneo DC. Palmar hyperhidrosis: clinical, pathophysiological, diagnostic and therapeutic aspects. An Bras Dermatol. 2016;91(6):716-25. 


\section{QUESTIONS}

1- Which anatomical site below is not affected by primary hyperhidrosis:
a) Face
b) Scalp
c) Inframammary region
d) Inguinal region

2- Check the incorrect alternative regarding hyperhidrosis:

a) There may be swelling of the fingers associated with the condition

b) It presents higher incidence in Western than in Japanese patients

c) It has greater intensity of symptoms during adolescence

d) Its improvement is common after the fourth decade of life

3- In relation to the sweat glands:

a) Eccrine glands are limited to urogenital and axillary regions

b) Apocrine glands are present in almost all body surfaces, predominantly in the palmar, plantar, axillary and craniofacial regions

c) They are increased in patients with palmar hyperhidrosis

d) Eccrine glands are stimulated by cholinergic fibers of the sympathetic nervous system

4- Is diagnostic criterium of palmar hyperhidrosis:

a) Presence of night sweats

b) Frequency of more than one episode per day

c) Age of onset $>25$ years

d) Bilateral and symmetrical sweat

5- What is the wrong alternative regarding the differential diagnosis of primary hyperhidrosis:

a) Hyperthyroidism, myasthenia gravis, Hodgkin's disease, alcoholism

b) Diabetes, Parkinson's disease, CNS tumors, sepsis

c) Pheochromocytoma, reflex sympathetic dystrophy, cancer of the chest cavity, use of venlafaxine

d) Menopause, hypothalamic disorders, tuberculosis, pregnancy

6- Which of the following factors influences the assessment of quality of life:

a) Socio-cultural aspects

b) Education

c) Health-related factors

d) All of the above

7- Regarding the Hyperhidrosis Disease Severity Scale (HDDS), check the incorrect alternative:

a) It presents a good correlation with other questionnaires modes b) It is complex, difficult to understand and demands a long time to be administered, and therefore it is difficult to apply

c) The improvement of one point in this scale was associated with a $50 \%$ reduction in sweat production, and of two points, with $80 \%$ reduction

d) It is specific for hyperhidrosis and provides qualitative measure of the condition severity

8- Regarding the clinical treatment of palmar hyperhidrosis, we can state that:

a) Astringent solutions act on the sweat glands, inhibiting sweat production

b) Iontophoresis consists of immersing the affected area in ionized solution with electric current of low voltage. It should be performed once a week for 30 to 40 minutes

c) Anticholinergic drugs act as antagonists of muscarinic receptors of sweat glands, competing with acetylcholine

d) Botulinum toxin blocks the release of noradrenaline in neuroglandular junction, resulting in decrease of impulse transmitted to the sweat gland

9- In the surgical treatment of palmar hyperhidrosis, it is incorrect to state that:

a) Currently it is considered that the video-assisted thoracoscopic sympathectomy is the most effective treatment for $\mathrm{PH}$ for presenting lasting functional results, being considered the best therapeutic option

b) Resection, cauterization, transection of the chain, ramicotomy and sympathetic chain clipping are the techniques used

c) The main adverse event in this procedure is compensatory hyperhidrosis occurring in a variable percentage of $10 \%$ to $40 \%$ of patients

d) Lesion performed in T2 or T4 ganglion has the same compensatory hyperhidrosis rates

10- Regarding astringent solutions, check the incorrect alternative:

a) They act on the opening of the sweat glands by blocking the sweat elimination

b) The most widely used solution is aluminum chloride 20-30\%, applied 2 to 3 times a week at night

c) The main adverse events are paresthesia and hypoesthesia in the applied area

d) Tannic acid, in a concentration of $2 \%$ to $5 \%$, can be used in mild cases

11- Regarding iontophoresis, check the incorrect alternative:

a) Immersion in solution with low-voltage electric current must be performed

b) It is a simple and practical method to be performed

c) Ionic changes promote temporarily blocking on the 
sweat glands

d) Treatment frequency is 4 times a week, with sessions of 30 to 40 minutes

12 - Regarding anticholinergic drugs, check the incorrect alternative:

a) They act on nicotinic receptors of sweat glands

b) Oxybutynin 5 to $10 \mathrm{mg} /$ day has results considered promising

c) Adverse events are important and include nausea, vomiting, dry mouth, urinary retention, intestinal constipation, postural hypotension, dyspepsia

d) Topic glycopyrrolate $0.5 \%$ to $2 \%$ has the advantage of reducing systemic adverse events of anticholinergic drugs

13- Regarding botulinum toxin, it is incorrect to state that:

a) It blocks the release of acetylcholine in the neuroglandular junction

b) It is a well-tolerated procedure by patients on hands and feet

c) It presents symptoms resolution by about 6 months, requiring repeated applications

d) The best indication is for individuals with pure axillary hyperhidrosis, as motor abnormalities in this region do not cause functional damage

14- Regarding psychotherapy, it is correct to state that:

a) It is not indicated for patients with primary hyperhidrosis

b) The main indication is for adults

c) It aims to control anxiety and insecurity, with consequent reduction of cortical stimulation to the autonomic nervous system

d) Adolescence is a period in which excess of emotional conflict prevents this type of treatment

15- Regarding the compensatory hyperhidrosis, check the incorrect alternative:

a) It occurs in a variable percentage of $10 \%$ to $40 \%$ of the series, but a small number of patients (5\%), usually submitted to interruption of the chain in the second ganglion level, suffers from a more severe form

b) The total amount of sweat is unchanged after sympathectomy: increased sweating in other parts of the body would represent a compensation of the organism in response to the procedure

c) It does not affect the results of patients undergoing sympathectomy

d) Although the exact mechanism remains unknown, there is a chance to occur a reflection mediated by the hypothalamus after the procedure on the sympathetic chain

16- Regarding percutaneous sympathectomy, check the correct alternative:

a) It is a complex procedure, requiring long hospitalization

b) It has low efficacy rates in control of palmar hyperhidrosis

c) It is performed with local anesthesia and sedation, with early return to daily activities d) It has no compensatory hyperhidrosis as reported complication

17- The percutaneous radiofrequency upper thoracic sympathectomy is:

a) A bad treatment option because it is a procedure with high rates of complications

b) It can be used as a safe option for the treatment of moderate and severe cases of palmar hyperhidrosis

c) It is also effective in controlling plantar hyperhidrosis

d) Lesions performed in T1 and T2 thoracic ganglia have the same effectiveness with low rates of compensatory hyperhidrosis

18- Regarding palmar hyperhidrosis, check the correct alternative:

a) It is a rare condition with low impact on the quality of life of affected individuals

b) It has simple treatment and excellent results

c) Severe cases should be subjected to treatment with botulinum toxin as a first option

d) It presents significant impact on quality of life of affected individuals, with repercussions on social, psychological and labor spheres

19- Regarding the diagnosis of palmar hyperhidrosis, check the correct alternative:

a) Complementary diagnostics methods are included in the diagnostic criteria

b) It is conducted through history and physical examination

c) It is essential to conduct the Minor's test (iodine-starch)

d) The biopsy of the affected area is mandatory for confirming the diagnosis

20- In compensatory hyperhidrosis, the best treatment option is:

a) Astringent agents

b) Oxibutinin

c) Repeat sympathectomy

d) Iontophoresis

\section{Answer key}

Inflammasomes and dermatology. 2016;91(5):566-78.

\begin{tabular}{llll}
\hline $1-\mathrm{A}$ & $6-\mathrm{B}$ & $11-\mathrm{B}$ & $16-\mathrm{D}$ \\
$2-\mathrm{C}$ & $7-\mathrm{D}$ & $12-\mathrm{D}$ & $17-\mathrm{D}$ \\
$3-\mathrm{D}$ & $8-\mathrm{A}$ & $13-\mathrm{A}$ & $18-\mathrm{A}$ \\
$4-\mathrm{C}$ & $9-\mathrm{C}$ & $14-\mathrm{A}$ & $19-\mathrm{A}$ \\
$5-\mathrm{B}$ & $10-\mathrm{C}$ & $15-\mathrm{B}$ & $20-\mathrm{B}$ \\
\hline
\end{tabular}

Papers

Information for all members: The EMC-D questionnaire is now available at the homepage of the Brazilian Annals of Dermatology: www.anaisdedermatologia.org.br. The deadline for completing the questionnaire is 30 days from the date of online publication. 